Fecha de recepción: marzo 2020 Fecha de aceptación: abril 2020 Versión final: junio 2020
Escenificación y legitimación
en los festejos patrios.
Reflexiones en torno a los
Bicentenarios en Argentina

María Paula Onofrio ${ }^{(1)}$

\begin{abstract}
Resumen: El artículo tiene por objetivo realizar un estudio comparativo de los regímenes de visibilidad y los modos de representación que se organizan en torno al Estado nacional argentino en los festejos por los Bicentenarios de la Revolución de Mayo (25 de mayo de 2010) y de la Independencia (9 de julio de 2016). Por un lado, se trata de identificar las imágenes oficiales, sus estéticas dominantes y los modos de organizar su puesta en escena y mediatización, en eventos organizados por dos gobiernos de signo político diferente y con orientaciones ideológicas disímiles, el del Frente para la Victoria y el de Cambiemos. Por el otro lado, se trata de analizar en cada caso los mecanismos de producción de sentido y su poder en la construcción de diferentes colectivos de identificación.
\end{abstract}

Palabras clave: Imagen - política - espectáculo - mediatización - Estado - colectivos de identificación.

[Resúmenes en inglés y portugués en las páginas 67-68]

(1) Es especialista en Diseño Comunicacional (FADU - UBA) y licenciada en Ciencias de la Comunicación (FSOC - UBA). Actualmente está finalizando su Maestría en Diseño Comunicacional de la Facultad de Arquitectura, Diseño y Urbanismo (UBA). En el ámbito académico, se desempeña como becaria UBACyT de maestría y como ayudante de cátedra de Diseño Gráfico (FADU - UBA). Además, participa en diferentes proyectos de investigación en el marco de la Universidad de Buenos Aires.

\title{
Introducción
}

Estado y espectáculo son términos redundantes. El Estado organiza formas de lo visible, se da a ver, se ofrece a la mirada, sugiere, por su manera de ponerse en escena, un modo de concebir formas del vivir juntos y, por ende, proyectos de identidad. Como afirma Debray, "un Estado que no diera nada a ver y a escuchar, sin rituales, monumentos y documentos, sería peor que un rey sin diversiones: una nada" (1995, p. 63). Son las modalidades del espectáculo las únicas que hacen época y sentido.

Inserto dentro del marco de una investigación sobre hegemonía discursiva e identidades 
políticas en la Argentina contemporánea, nuestro artículo ofrece resultados preliminares de un estudio comparativo de los regímenes de visibilidad ${ }^{1}$ y los modos de representación que se organizan en torno al Estado nacional argentino en los festejos por los Bicentenarios de dos fechas patrias: la Revolución de Mayo (25 de mayo de 2010) y la Independencia de las Provincias Unidas del Río de la Plata (9 de julio de 2016).

Nos proponemos estudiar, por un lado, las estéticas dominantes y los modos de organizar la puesta en escena en cada caso, teniendo en cuenta que fueron eventos organizados desde el Estado nacional, pero a cargo de dos gobiernos de signo político diferente y con orientaciones ideológicas disímiles, el del Frente para la Victoria y el de Cambiemos. Por el otro lado, se trata de analizar los mecanismos de producción de sentido y su poder en la construcción de diferentes colectivos de identificación. En el marco de la Teoría de los Discursos Sociales (Verón, 1987), nos interesa pensar cómo, en relación a la celebración de una fecha patria, uno y otro gobierno a cargo del Estado nacional sugieren formas litúrgicas que pueden fundamentar liderazgos e identidades políticas diferentes.

Como intervenciones sobre el espacio público, este tipo de espectáculos realiza una escansión de la temporalidad del sistema de medios al introducir un elemento heterogéneo e imprevisto (en el sentido de que no es producido por el sistema mediático); son, en palabras de Dayan y Katz (1992), tácticas de mediatización. Entendemos, entonces, que un análisis sobre la faceta espectacular de la política contemporánea es, esencialmente, el estudio de su mediatización. En pos de dicha observación, se tomó como material de análisis todas las transmisiones oficiales emitidas en directo por la TV Pública con motivo de ambas conmemoraciones. A partir de un análisis de tipo cualitativo y, específicamente, desde la perspectiva del Análisis del Discurso, nos preguntamos por el régimen de visibilidad según la modalidad enunciativa desarrollada en cada estrategia discursiva político-mediática.

La dispositio del artículo se corresponde con el orden cronológico de los acontecimientos: en primer lugar, nos ocuparemos del Bicentenario de 2010 y, luego, de la celebración de 2016. Como resultado del análisis, afirmamos que mientras el Bicentenario de la Revolución de Mayo adoptó la forma de una típica Fiesta Maya, la modalidad enunciativa predominante del Bicentenario de la Independencia fue el show televisivo. Finalmente, a modo de cierre, se ofrecen algunas consideraciones finales.

\section{Bicentenario de la Revolución de Mayo (25 de mayo de 2010)}

El Bicentenario del 25 de mayo de 2010 fue, sin dudas, la apuesta más espectacular del kirchnerismo en el poder. Con motivo de la celebración de los 200 años de la Revolución de Mayo de 1810, el entonces gobierno nacional, si se nos permite la metáfora, tiró la casa por la ventana. Al caer la tarde del viernes 21 de mayo de 2010, la ex presidenta de la nación, Cristina Fernández de Kirchner, dejó inaugurado el Paseo del Bicentenario, ubicado en la Avenida 9 de Julio. Allí, los festejos se extendieron durante cinco días consecutivos y culminaron en la madrugada del 26 de mayo. Millones de personas se volcaron a las calles durante aquellos días para disfrutar de las más variadas atracciones y, aunque también hubo algunas actividades en otras provincias, Buenos Aires fue el epicentro. 
Sobre la Avenida 9 de julio, entre Corrientes y Belgrano, se instaló: una Feria provincial, en donde estaban representadas las 24 provincias con stands temáticos y gastronómicos; seis espacios dedicados a asuntos específicos como Ciencia y Tecnología, Juventud y Educación, Ambiente, Cultura, Derechos Humanos y Producción; una gran maqueta a escala real de la Casa de la Independencia; cuatro escenarios; y dos locomotoras históricas en exhibición (La Porteña y La Patria). Hubo varios desfiles: un desfile militar, que contó con la participación de bandas de regimientos, escuadrones de caballería montados, unidades históricas del Ejército con trajes de época y el escuadrón banderas; un desfile federal, en el que cada provincia desplegó intervenciones callejeras representativas; el desfile de la integración representó "la unión fraternal entre pueblos y la integración de la Argentina con Latinoamérica y el mundo"2; y un desfile de autos y motos antiguas, recorrió el Paseo del Bicentenario. Durante todos los días y hasta altas horas de la noche, se llevaron a cabo numerosos recitales en los que participaron centenares de artistas. Por su parte, la presidenta asistió al tradicional Tedeum en la Basílica de Luján, e inauguró el Centro Cultural del Bicentenario, en la ex sede del Correo Central de Buenos Aires, y la Galería de los Patriotas Latinoamericanos, en la Casa Rosada. Los presidentes latinoamericanos, Hugo Chávez, José Mujica, Fernando Lugo, Evo Morales, Rafael Correa, Luiz Inacio Da Silva y Sebastián Piñera fueron, entre otros, los invitados de honor de la ex mandataria argentina. Al caer la noche del 25 de mayo, tuvo lugar un mapping 3D proyectado sobre la fachada del Cabildo y, luego, se desplegó el desfile histórico-artístico organizado por la Compañía Fuerza Bruta $^{3}$. Ya a las 2 a.m. del miércoles 26, el himno a cargo de los artistas del Bicentenario y los fuegos artificiales despidieron a los presentes. La celebración fue monumental; se estima que casi tres millones de personas se volcaron a la calle sólo en el último día de festejo. Tenemos una hipótesis al respecto: el Bicentenario de 2010, a través de una marcada memoria comunicacional, adoptó la forma de una típica conmemoración cívica nacional: la Fiesta Maya. Situación extraordinaria que rompió la cotidianeidad y generó un clima positivo entre los participantes, el espectáculo político puso en escena una totalidad inclusiva que forjó -aunque por esos pocos días- un colectivo específico: "nosotros, los presentes". A continuación, dedicaremos siguiente apartado al desarrollo de estas premisas.

\section{El acto como ritual: escenificación e identificación}

Históricamente, las conmemoraciones cívicas han servido para generar identificaciones comunes, forjar imaginarios sociales y construir sentidos de comunidad. Se trata de festejos oficiales que invitan a individuos de diferentes jerarquías y tradiciones a confluir, a partir de un entusiasmo compartido y por un tiempo acotado, en el espacio público. Las representaciones simbólicas que toman relevancia durante las ceremonias erigen una forma de vivir en sociedad, al tiempo que legitiman al gobierno que las organiza. Concentrando a los hombres en "el espacio uno e indivisible del ardor cívico" -sostiene Rosanvallon en La sociedad de iguales (2012)-, las fiestas públicas generan cohesión social y delimitan modos específicos del ejercicio de la ciudadanía. 
En Argentina, este fue el caso, desde su primer aniversario en 1811, de los festejos en conmemoración de la Revolución de Mayo. Durante décadas, las Fiestas Mayas se presentaron como un momento extraordinario que rompía la cotidianeidad y generaba un clima positivo que propiciaba el entusiasmo general. Esta generalización se mostraba, a su vez, incluyente, universalizando a los participantes en una totalidad. Ritual cívico, las primeras Fiestas Mayas constituyeron, según Halperin Donghi (1997), un momento culminante en la creación de una nueva liturgia revolucionaria. Con el paso del tiempo y pese a los cambios de gobierno, la celebración de Mayo se fue afirmando en el calendario de la ciudad, "constituyendo un momento particular donde la jerárquica sociedad que las festeja se iguala al compartir un entusiasmo totalizante detrás de la fecha conmemorada pero también de la causa revolucionaria en plena marcha" (Gómez, 2013). Con modalidades festivas, populares y lúdicas, los festejos ponían en escena en el espacio público un colectivo de identificación amplio, que las diferentes autoridades buscaban, a su vez, referenciar como síntoma de apoyo a su gestión. Sin embargo, hacia fines del siglo XIX y de cara al Centenario, las Fiestas Mayas sufrieron un proceso de "estadificación", escolarización y militarización: se reemplazó "la fiesta" por "la Patria" (Sigal, 2006, p. 119). Con una presencia más fuerte del Estado y objetos de interés basados en la erección de monumentos, museos y estatuas, el culto a los próceres quedó en manos de la escuela y el ejército. Según Bertoni, en la nueva modalidad del espectáculo oficial "la sociedad dejó de ser un ejecutante del rito para pasar a ser 'público"' (1992, pp. 81-82).

Consideremos ahora al Bicentenario de 2010. Entre el 21 y el 25 de mayo, el pueblo se volcó masivamente a la calle; esa fue la postal panorámica predominante. La comunión de los cuerpos presentes y el clima festivo fueron una constante que remarcaron desde la organización del evento hasta los medios más reticentes al gobierno kirchnerista. Por un lado, tuvo lugar una suerte de igualdad transclase momentánea:

Calles que a diario están congestionadas de autos y smog hoy muestran un panorama diferente: miles de personas, familias enteras y muchos jóvenes con cámaras de fotos en mano y algún distintivo celeste y blanco tomaron las principales arterias porteñas como peatonales (Ámbito Financiero, 23/05/2010).

Y unas líneas más abajo el periodista Diego González del diario Ámbito Financiero ${ }^{4}$ sentenció: "personas de diferentes extractos sociales disfrutando pacíficamente de una celebración única. Quizás dentro de una semana uno esté cortando una avenida y el otro indignado desde su auto, pero eso hoy no importa. Parece que hoy somos todos uno".

Desde nuestra perspectiva, no podemos afirmar la universalidad en reconocimiento. Pero sí inferir, a través de la representación audiovisual testimonial de sujetos y situaciones, la construcción de un colectivo amplio e indiferenciado, una totalidad con capacidad inclusiva cuyo sentido fundamental era estar ahí y estar juntos. Siguiendo la distinción de planos visuales de Cingolani $(2015)^{5}$, advertimos que los recortes operados por los sucesivos encuadres de cámara actuaron en dos direcciones complementarias: en primer lugar, los planos generalizantes construyen un colectivo homogéneo por definición. Las panorámicas en picado transforman a todos los cuerpos individuales en uno solo (Figura 
1). Cuerpo brutal, indefinible, voluminoso, desbordante, este tipo de plano pone en escena la dimensión multitudinaria del evento, la apropiación simbólica del espacio público, y el comportamiento armonioso y festivo del grupo.

En segundo lugar, los planos grupales tienen un fuerte valor acumulativo, a partir de los rasgos visibles de los cuerpos mostrados: hay jóvenes, familias, adultos mayores y niños, pertenecientes a distintos sectores sociales. Se muestra así un colectivo como totalidad que supone, a su vez, la inclusión de diferentes partes o grupos. Además, los símbolos localizables a través del plano más cercano remiten a una identidad nacional antes que partidaria, forjando el compromiso del colectivo con la conmemoración patria (Figura 2). La alternancia constante entre ambos planos, el que muestra la totalidad homogénea y el que incluye a las diferentes partes en la "masa" (DaMatta, 2002), exhibió la emergencia de una "communitas existencial"; esto es, "una totalidad relativamente indiferenciada de individuos" espontánea, concreta e inmediata (Turner, 1988, p. 103) .
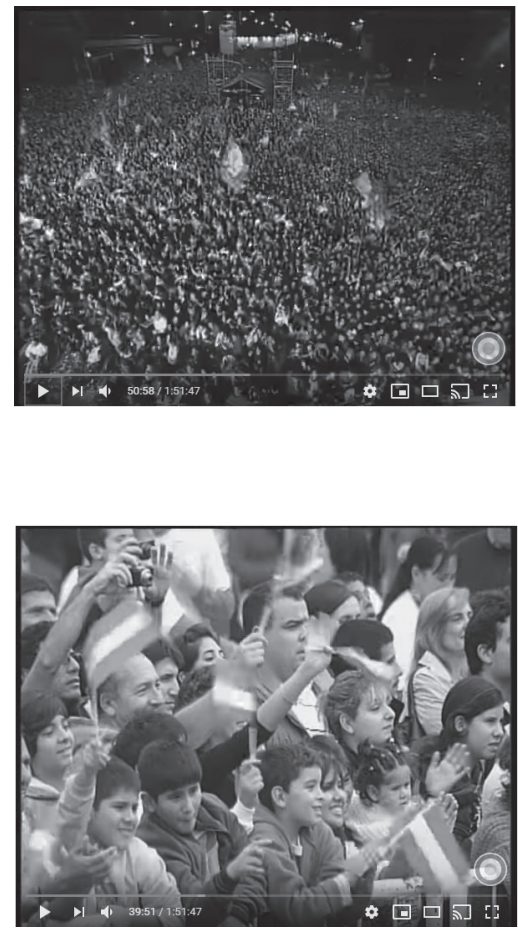

Figura 1. Plano generalizante Bicentenario 2010.

Fuente: YouTube, TV Pública Argentina.
Figura 2. Plano grupal Bicentenario 2010 II. Fuente: YouTube, TV Pública Argentina. 
Producto del carácter ritual del festejo cívico, esa congregación colectiva televisada, en vivo y en directo, fue momentánea y extraordinaria. En los años que siguieron, según Fernández y Cingolani (2018), las celebraciones del 25 de mayo, al igual que la mayoría de los actos de gobierno de Cristina Fernández de Kirchner, lejos de invocar una forma de comunidad nacional, fueron aferrándose progresivamente al régimen de visibilidad típico de la ceremonia partisana; esto es, un régimen de visibilidad que se define porque escenifica el liderazgo como capacidad de conducción de una fuerza política y la pertenencia a una identidad acotada, singular, de partido.

Por otro lado, en sintonía con las tradicionales Fiestas Mayas, el Bicentenario de 2010 mostró un clima de entusiasmo generalizado. La disposición de los festejos, la irrupción de las masas, y la diversidad de los participantes, forjaron una atmósfera positiva que contribuyó a fortalecer el tono épico del rito. Además, la celebración de los 200 años supuso la reivindicación de la alegría como estado de ánimo revolucionario:

Déjenme decirles que me siento muy orgullosa. Cuando vi desfilar las provincias, ayer las colectividades, con esos cientos de miles de hombres y mujeres, chicos y ancianos, celebrando con alegría, con alegría, veía frases de Jauretche: los pueblos deprimidos y tristes no pueden cambiar nada. Los pueblos con alegría, que celebran su historia, toda su historia completa, son los pueblos que podemos seguir transformando y cambiando. (Cristina Fernández de Kirchner, 24 de mayo de 2010)

A través de una cita de autoridad como forma de "enunciación patrimonial" (Paveau, 2013) ${ }^{7}$, la presidenta define a la alegría como condición sine qua non de la transformación social, enlazando simbólicamente al festejo en cuestión con sus predecesores. Al mismo tiempo, las palabras presidenciales ponen de relieve otro elemento propio de las fiestas cívicas: la comunión de los participantes en el espacio público, un aquí y un ahora compartidos.

El Bicentenario fue, antes que nada, una experiencia intransferible de la que gozaron los asistentes: intervenir en los desfiles, recorrer los stands, participar de las actividades propuestas, ocupar las calles hasta altas horas de la noche, comer, jugar y bailar. En este sentido, el desfile histórico-artístico organizado por la compañía Fuerza Bruta nos sugiere una particular forma de espectáculo que se inserta en un complejo entramado de festejoemoción-participación. Bajo la lógica del pastiche y el kitch, aquel monumental desfile de cierre presentó, a través de un montaje performático, dieciocho escenas que, con diferentes recursos, condesaban visualmente momentos históricos, aspectos sociales y culturales, y hasta procesos políticos y económicos de la historia argentina ${ }^{8}$.

Según Malala González, más que apelar a una distancia crítica capaz de problematizar el contenido o el propósito conmemorativo de cada escena, "el desfile proporcionó otros vínculos y apropiaciones en la ciudadanía, donde el entretenimiento y el impacto emocional habrían resultado las relaciones más convocantes" (2015, p. 120). Antes que espectador, el público asistente fue parte de aquella celebración. Experiencia emocional, a la vez que individual y colectiva, la presencia de cuerpos en el espacio urbano fue complementaria $-\mathrm{y}$ 
constituyente- de la puesta en escena carnavalesca encargada de clausurar la fiesta oficial. La conmoción resultó de la convivencia multitudinaria en el espacio público intervenido, inscripta en el orden de lo corporal. Lo que se privilegió, entonces, fue una producción estética del "aquí y ahora" teatral donde lo participativo, físico, receptivo-sensorial fueron los factores primordiales.

Ahora bien, si, siguiendo a Malala González, consideramos el carácter efímero de los monumentos performáticos, el Bicentenario fue, más que ninguna otra puesta en escena del gobierno kirchnerista, un acto convivial (Dubatti, 2007). Esto es, se trató esencialmente de un puro acontecimiento establecido sobre el espacio público intervenido por realizadores y espectadores, como un ritual entre ambos. Congregados allí los cuerpos presentes, el Bicentenario tuvo lugar durante un tiempo específico y en un lugar determinado.

Finalmente, si nuestra pregunta es por los procesos de legitimación e identificación en la liturgia del Bicentenario, debemos considerar la unidad simbólica que resulta del carácter ritual del evento político. Por un lado, siguiendo a Auge, podemos afirmar que "la actividad ritual crea identidad" (1998: 26); se trata del colectivo que podemos definir como "nosotros, los presentes". Por el otro lado, esa comunión representa un signo de legitimidad en sí mismo a partir de la movilización y la presencia popular en el espacio público: "las personas piensan del poder aquello vinculado a lo que ven: su esplendor, su ceremonial, su ritualidad", afirma González (en Nun, 2005: 244).

Pero, en tanto intervención sobre el espacio público, el Bicentenario fue, a su vez, mediatizado. Si se estima que durante los cinco días asistieron seis millones de personas al festejo, muchísimos más fueron los ciudadanos que lo vieron televisado. En este sentido, no se advierten en aquella puesta en escena estrategias discursivas definidas "en busca del buen contacto" (Verón, 2001) en el orden indicial que apunten a la inclusión del público mediático. Además, la simultaneidad de actividades, la dimensión hiper del espectáculo (Lipovetsky y Serroy, 2015) y la disposición topográfica dificultaron la televisación de los festejos.

En este sentido, podemos afirmar que la modalidad de fiesta cívica del Bicentenario de 2010 definió a los presentes (o segundos) como los únicos destinatarios directos de aquel espectáculo político. Sin embargo, la mediatización televisada, al trabajar sobre la indicialidad, sobre la mostración y la identificación, permite -en el Bicentenario, en particular, casi como excepción al régimen de visibilidad predominante de los gobiernos de Cristina Fernández de Kirchner- concebir a ese pueblo encarnado en la multitud que colma las calles como un colectivo que es posible de superponer con los habitantes de la nación. En otras palabras, el carácter multitudinario e indiferenciado del colectivo escenificado y la mostración de símbolos patrios facilitaron la relación representacional del tercero con el segundo.

En conclusión, podemos afirmar que el Bicentenario de 2010, evocando la tradición de las Fiestas Mayas, definió al pueblo como el destinatario de los festejos. Pero el pueblo en tanto colectivo movilizado en el espacio público; en tanto ciudadanía participante. Multitud abigarrada y festiva, colectivo social multiplicado en millones de personas que se manifestaron, que gozaron y cantaron, que bailaron y conversaron, que miraron y preguntaron, que se emocionaron y se sorprendieron. Cuerpos afectados, emocionalmente comprometidos, que se unen en un ritual épico y multitudinario. Tangencial a las lógicas 
de comunicación de la política televisada, la identidad se refuerza en la comunión de los presentes y se debilita en el caso de los públicos mediáticos, que en ningún caso son interpelados de manera directa pero que reingresan a la escena a través de la identificación indicial con el colectivo escenificado. Más allá de eso, el Bicentenario del 25 de Mayo de 2010 es -coherente con la imaginación política del kirchnerismo- categórico: el ejercicio de la ciudadanía está en la calle antes que en los medios de comunicación.

\section{Bicentenario de la Independencia (9 de julio de 2016)}

El 9 de julio de 2016, a pocos meses de haber asumido el gobierno nacional, Cambiemos también tuvo su Bicentenario. Lejos de la memoria de la celebración de mayo de 2010, se trató de un festejo más tradicional, discreto y austero. El carácter federal y descentralizado que asumió el segundo Bicentenario fue otro de los rasgos distintivos. Así como algunos años atrás el Bicentenario de Mayo había puesto en valor ciertos modos de imaginar la política ligados a la fuerza gobernante de entonces, los 200 años de la Independencia nacional también pusieron en juego algunas cuestiones del imaginario político de Cambiemos. La conmemoración de los doscientos años de Independencia comenzó unas horas antes del 9 de julio con la transmisión televisiva de la vigilia "Celebremos la Independencia". El especial de TV que duró alrededor de tres horas fue emitido exclusivamente por la TV Pública y contó con la conducción de Karina Mazzocco y Damián Glanz. A través de las sucesivas introducciones de los presentadores, la pantalla chica mostró un breve discurso de Mauricio Macri desde la Quebrada de Humahuaca y diversos recitales que tuvieron lugar en escenarios de todo el país. Sólo por mencionar algunos, Karina "La Princesita" se presentó en Santa Fe; Maximiliano Guerra, en Buenos Aires; Iván Noble, en Formosa; el grupo Babasónicos tocó en Chaco; y Juan Carlos Baglietto cantó en Tucumán. Además de los recitales y del discurso presidencial, el especial televisivo incluyo informes grabados alusivos a la fecha patria y una sección en la que los conductores interactuaban con el público a partir del hashtag \#FelizIndependencia. A la medianoche, Mauricio Macri volvió a la pantalla para entonar, al pie del Monumento a los Héroes de la Independencia, las estrofas del Himno nacional.

El 9 de julio por la mañana, el presidente fue recibido en Tucumán por el gobernador de la provincia, Juan Manzur. Tras un desayuno con invitados especiales, estuvo presente para el izamiento de la bandera en la Casa de Gobierno provincial. Luego, la comitiva oficial se desplazó hasta la Iglesia Catedral para participar del tradicional Tedeum. El acto central de la fecha se desarrolló en la Casa Histórica de Tucumán en donde, tras firmar el "Acta del Bicentenario" junto a otros gobernadores, el primer mandatario dio su segundo discurso. Pasado el mediodía, Macri participó de un gran desfile cívico militar en la Avenida Mate de Luna. Finalmente, última actividad programada, el domingo 10 se realizó, en Buenos Aires, un desfile militar sobre la Avenida del Libertador, entre Salguero y el Campo Argentino de Polo, en Palermo.

Hasta aquí, una muy breve descripción de lo que fueron los hechos. En la siguiente sección, nos dedicaremos a estudiar los regímenes de visibilidad y los procesos de identifica- 
ción allí configurados. Si definimos a la puesta en escena del Bicentenario de 2010 como una fiesta cívica, sostenemos que el show televisivo es la dinámica predominante de los festejos de 2016. Por último, advertimos dos lógicas que, en oposición a su precursor, definen a este segundo festejo patrio: una lógica descentralizada y otra vinculada a la austeridad.

\section{El show televisivo; o cómo ampliar la destinación del espectáculo político}

Seis años después del monumental festejo por los doscientos años de la Revolución de Mayo, la gestión macrista optó por una celebración más modesta para el Bicentenario de la Independencia. Lejos del carácter ritual, la legitimidad del evento a cargo de Cambiemos cobró pleno sentido a partir de su mediatización.

En La mediatización, entre los cuerpos ciudadanos y el cuerpo presidencial (2015), Gastón Cingolani identifica tres tipos de regímenes audiovisuales de la discursividad política: mediación, contacto y espectáculo. El primero consiste en la palabra de la figura presidencial en diálogo con un periodista o entrevistador que ejerce discursivamente el rol de mediador entre el político y el tercero, la audiencia. El segundo se erige por la mirada a cámara para establecer contacto directo por el eje de "los ojos en los ojos" (Verón, 1983); esta modalidad lleva al tercero a homologarse con el segundo de ese discurso, incorporándose a la escena y disolviendo a ambos en una misma figura. Y, por último, la modalidad de espectáculo es aquella en la que el gobernante dispone corporalmente su discurso para un auditorio presente en la misma espacialidad en cuerpos visibles y audibles, sobre los que posa su mirada. El espectáculo discurre como una escena entre copresentes, donde el que hace las veces de auditorio mantiene una relación protética del público en la pantalla (Barreiros, 2005), como en cualquiera de las formas del show televisivo 9

Retomando las categorías de Cingolani, sostenemos que el Bicentenario de la Independencia fue un show televisivo en dos sentidos: por un lado, los dos discursos del presidente, Mauricio Macri, en el marco de la celebración se inscriben en la modalidad de espectáculo ${ }^{10}$. Por el otro lado, más allá de los ritos de continuidad (como el Tedeum o el desfile militar), cuyos modos de mostración fueron similares en ambos festejos, el Bicentenario de 2016 optó por otras dinámicas que incluyeron lógicas y especificidades propias de la televisión.

Empecemos por el discurso presidencial. El 8 de julio, en el marco del especial de la $T V$ Pública, "Celebremos la Independencia", Mauricio Macri dio su discurso de inauguración de los festejos del Bicentenario 2016, en directo desde Humahuaca, provincia de Jujuy. La disposición topográfica se correspondió con la modalidad de espectáculo: el gobernante dispuso corporalmente su discurso para un auditorio presente en la misma espacialidad y, en conjunto, todos estaban siendo parte, a su vez, de un espacio intramediático. Allí identificamos dos tipos de recortes predominantes operados por los encuadres de cámara que incidieron en los procesos de identificación: el plano medio de la figura presidencial y los planos generalizantes.

El plano medio sostenido ante el cuerpo del político, quieto y apacible, encontró, en reiteradas ocasiones, la mirada presidencial, habilitando el contacto directo por el eje de "los 
ojos en los ojos" (Verón, 1983). Aunque breves, fueron esos momentos los que habilitaron una interpelación directa al receptor televisivo en tanto ciudadano. Además, a través de los recursos de la iluminación y del foco, el plano medio recortaba a la figura de Macri sobre un grupo de personas de fondo, cuyos rasgos tipológicos generales aún reconocibles se traducían en una pertenencia regional específica, el norte argentino. La mediatización audiovisual de aquellos cuerpos ligaba así al presidente a un sector representativo del interior del país (Figura 3) ${ }^{11}$.

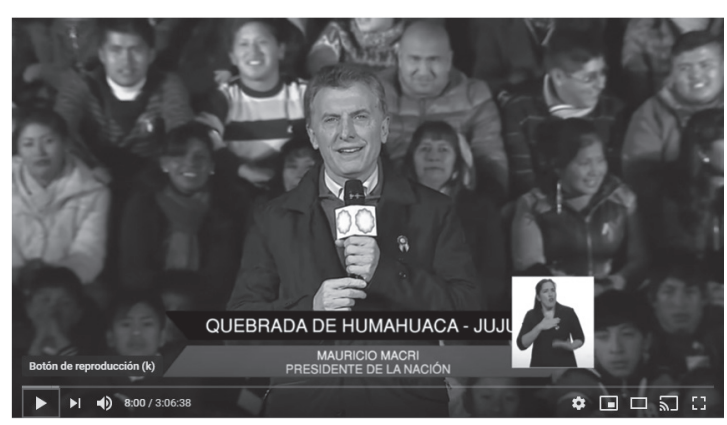

Figura 3. Discurso de Mauricio Macri en la vigilia del 9 de julio de 2016. Fuente: YouTube, TV Pública Argentina.

Por otra parte, la irrupción de los planos generalizantes contribuyó a la definición de un colectivo indiferenciado que, en la construcción discursiva audiovisual, bien podría simbolizar a la "gente", a los "ciudadanos", a los "argentinos". En el plano abierto, la mostración visual de los abundantes símbolos patrios agitándose entre la multitud, contribuía a la legitimidad de la palabra presidencial, al tiempo que reforzaba la construcción de un colectivo de índole nacional. La proyección lumínica de fondo con los colores de la bandera argentina refuerza esa identidad (Figura 4).

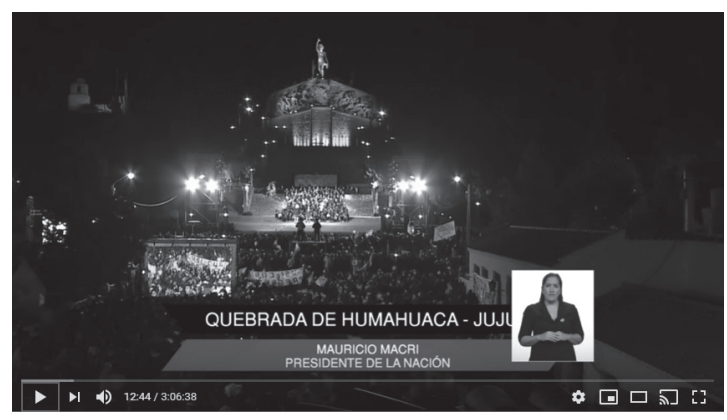

Figura 4. Plano generalizante Bicentenario 2016. Fuente: YouTube, TV Pública Argentina. 
Al día siguiente, Mauricio Macri emitió su segundo discurso desde la Casa Histórica de Tucumán. La modalidad de espectáculo se mantuvo, pero, en este caso, la mediatización visual de la puesta en escena combinó otra de dinámica de planos. En esta ocasión, a los planos generalizantes y al plano medio de la figura presidencial, se le agregaron otros dos: los planos grupales y los planos individualizantes. Los planos grupales mostraron, alternativamente, a los funcionarios e invitados especiales en las primeras filas y a otros conjuntos de personas, en principio no identificables, pero quienes, en función de sus características estilísticas y los símbolos patrios que sostenían, podían traducirse como vecinos o ciudadanos. Por su parte, los planos individualizantes reforzaron este sentido a partir de la inclusión de rostros representativos de aquel colectivo. Al trabajar sobre la indicialidad, sobre la mostración y la identificación, la mediatización televisada de ese colectivo de ciudadanos facilitó la identificación e inclusión de los espectadores televisivos en la escena. Hasta aquí el show televisivo como régimen exclusivo de la discursividad presidencial durante el Bicentenario. Pero también, y es un factor constitutivo del segundo Bicentenario, la vigilia "Celebremos la Independencia" fue, literalmente, un programa de TV, un show televisivo. Durante las tres horas de trasmisión hubo notas en vivo y grabadas, informes especiales, interacción con los telespectadores y móviles en diferentes lugares. El discurso del presidente fue una pieza más entre otras, articuladas todas ellas mediante la figura del presentador. Y los presentadores, ya lo advirtió Verón hace muchos años atrás, mientras hablan, dirigen su mirada al ojo vacío de la cámara: nos miran. "Está ahí, lo veo, me habla", fue la frase de Verón respecto del entonces nuevo modo de enunciación del noticiero televisivo. Allí el contacto es el fundamento de la relación entre el enunciador y el enunciatario y el soporte mismo del vínculo de confianza entre ambos [Fig. 5]. Pivote organizador, el eje de la mirada (eje o-o), funciona también como conector: su deslizamiento puede tomar a su cargo operaciones de transición o de articulación. Entonces, aquella noche de vigilia los conductores del especial emitido por la TV Pública, Karina Mazzocco y Damián Glanz, no sólo le hablaban a cada uno de los telespectadores, sino que también los invitaban a asistir junto a ellos al discurso presidencial y a los recitales que estaban teniendo lugar en simultáneo en los diferentes puntos del país.

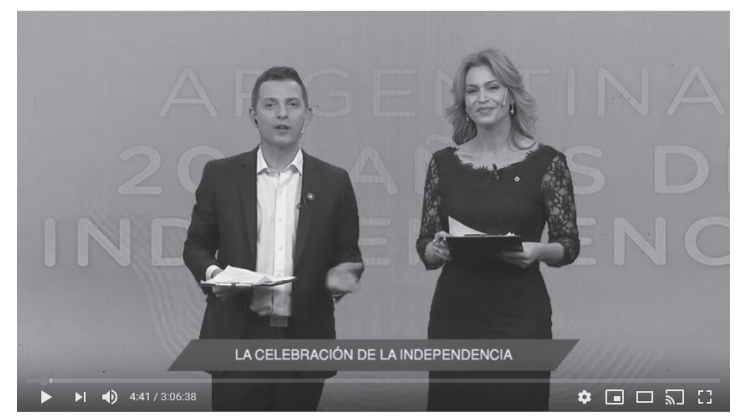

Figura 5. "Celebremos la Independencia”, transmisión de la TV Pública, Bicentenario 2016. Fuente: YouTube, TV Pública Argentina. 
Además de la figura de los presentadores, otro recurso que reforzó decididamente el contacto con los telespectadores fue la interacción vía Twitter. A través de ese medio con base en Internet, la opinión del público fue incluida en el curso del programa y el espectador televisivo podía intervenir del espectáculo. En consecuencia, el colectivo que se gesta a través de esta dinámica excede a los asistentes a cada espectáculo e incluye a todo aquel que participe desde su casa.

A partir de estas consideraciones, podemos afirmar que, en función de ciertas estrategias discursivas político-mediáticas como la mirada a cámara y la inclusión de las redes sociales, la celebración del Bicentenario de la Independencia tiende a incorporar al tercero, la audiencia, en la escena. Pero en este caso, a diferencia de los festejos de 2010, el público mediático ya no sólo ingresa a la escena mediante los procesos de identificación con el colectivo escenificado, sino que también es en gran medida el destinatario directo del espectáculo, traduciéndose en un colectivo tan amplio como desegmentado. A partir del colectivo escenificado en los actos y a falta de una categorización estricta por medios lingüísticos en los discursos presidenciales, podemos definir a ese colectivo inclusivo como "nosotros, los ciudadanos" o "nosotros, los argentinos".

Por último, nos interesa destacar otras dos lógicas que, más allá de la dinámica televisiva que adoptó el festejo patrio, contribuyeron a ampliar los procesos de identificación del Bicentenario como espectáculo político. Por un lado, la mostración de los festejos estuvo regulada por una lógica descentralizada. En lugar de un festejo único y monumental, hubo recitales y espectáculos en diferentes puntos del país, a los que cada argentino podía tener acceso, a su vez, a través del especial televisivo. No se trató de la unidad simbólica del acto ritual; si no que la comunión fue, a través de la conectividad de los medios masivos y digitales, cada uno desde su lugar, desde su provincia, desde su casa. En esta línea, Mauricio Macri insistió en interpelar de forma individual a los argentinos:

Y hoy, parado acá, en Humahuaca, le pido a todo el país lo mismo. Que cada argentino se anime a ser protagonista, que cada uno crea en sí mismo, crea en sus capacidades, en su talento, en su creatividad y que no tengamos miedo. (Mauricio Macri, 8 de julio de 2016)

Porque nunca es fácil, no fue fácil en ese momento ni es fácil hoy asumir ser independientes, asumir ser libres, porque eso conlleva una responsabilidad, porque no se agota en decir "el país es independiente, este Estado es independiente". Es cada ciudadano, cada uno de nosotros asumiendo ese rol, ese rol de responsabilidad que significa que no le podemos echar la culpa a nadie de lo que nos suceda porque somos los dueños de nuestro destino. (Mauricio Macri, 9 de julio de 2016)

Y además hoy, con este día maravilloso, les quiero pedir otra cosa más que tiene que ver con que entendamos que un país es como una familia y lo que hace algún integrante de la familia siempre en algún lugar repercute sobre los demás. Ahí fue el mensaje de la empanada, que espero que hayan visto; hasta esa cosa tan pequeñita requiere el esfuerzo de muchos argentinos y que cada 
uno de nosotros dé lo mejor de sí. Y cuando digo lo mejor de sí, me refiero a que cada alumno se esfuerce por aprender, se esfuerce por superarse, que cada maestro ponga todo ese amor que pone en enseñarles pero también en exigirles y en evaluarlos para asegurarnos de que ellos tengan las herramientas para un mejor futuro. (Mauricio Macri, 9 de julio de 2016)

De estos fragmentos se desprende la idea de que la unidad, en tanto todo, no es una entidad per se; sino que se trata de la convergencia de individualidades ("cada argentino", "cada ciudadano" e "integrante de la familia"), que confluyen en un colectivo nacional. Lejos del imaginario kirchnerista, el gobierno de Cambiemos nos sugiere una concepción agregativa, individual y conectiva del ejercicio de la ciudadanía.

Por el otro lado, hay otra lógica que organiza el Bicentenario y tiene que ver con la austeridad. Después de la vigilia "Celebremos la Independencia", lo que resta es lo protocolar: el Tedeum, un acto modesto en la Casa Histórica de Tucumán, que incluyó la firma de un acuerdo entre el presidente y los gobernadores provinciales, y dos desfiles militares, uno en Tucumán y el otro en Buenos Aires. La apuesta de Cambiemos se inclina por mostrar un Estado achicado antes que monumental: las puestas en escena nos sugieren la imagen de un gobierno sobrio, preciso y lacónico. En este sentido, retomando a Soledad Montero (2018), podemos afirmar que el partido gobernante, recoge y devuelve una determinada "porción" de la doxa. No es difícil comprobar que los denominados gobiernos populistas fueron cuestionados históricamente por el agrandamiento del Estado y los gastos excesivos en su nombre. Incluso el Bicentenario de 2010, que en líneas generales tuvo una amplia aprobación, fue puesto bajo la lupa por los medios masivos debido su costo colosal ${ }^{12}$. Dentro de ese lugar común que desaprueba el "derroche estatal", Cambiemos propuso un festejo austero, legitimándose en el "se dice" de la opinión común. Nuevamente, "la gente" como entidad colectiva cristalizada es evocada, en este caso, a través de su creencia.

El Bicentenario de la Independencia, en conclusión, tendió a ampliar la destinación de los festejos, a través de ciertas estrategias que contribuyeron decididamente a incluir a los públicos mediáticos. La disposición de los discursos presidenciales y la dinámica televisiva invitaron a las audiencias a ser parte de los festejos, principalmente, mediante la interpelación directa y la construcción de un colectivo amplio y desegmentado que, a diferencia del Bicentenario de 2010, no se limitó a los presentes. También en contraposición al festejo anterior, la lógica descentralizada como elemento constitutivo de la celebración incidió decisivamente en la definición de un colectivo de tipo nacional ("nosotros, los argentinos"); y la mostración de cierta mesura y austeridad legitimaron al gobierno, al posicionarse en un lugar común sobre los gastos del Estado que se ancla en el saber colectivo, anónimo e impersonal de la comunidad. El Bicentenario muestra, en este sentido, la apuesta de Cambiemos por alejarse de cierta configuración del espectáculo político significativamente arraigada en la tradición política argentina y que remite tanto a los gobiernos peronistas como al radicalismo. 


\section{Conclusiones}

Con apenas una diferencia de seis años, la Argentina celebró dos Bicentenarios: el 25 de mayo de 2010 y el 9 de julio de 2016. Nuestro trabajo tuvo como objetivo realizar un estudio comparativo de los regímenes de visibilidad y los modos de representación que se organizaron en torno al Estado nacional argentino en ambas celebraciones patrias, teniendo en cuenta que fueron eventos a cargo de dos gobiernos de signo político diferente y con orientaciones ideológicas disímiles, el del Frente para la Victoria y el de Cambiemos. Nos preguntamos cómo uno y otro gobierno procuró performar colectivos a través de las puestas en escena allí desplegadas.

Los espectáculos políticos que acabamos de describir no agotan, por supuesto, las identificaciones y memorias, desplegadas por uno y otro partido de gobierno, pero ofrecen pistas sobre sus modos de imaginar la política. Cada forma del espectáculo político estatal, advierten Cingolani y Fernández (2019), lleva inscripta la concepción, no tanto de cómo es la sociedad, sino de cómo un proyecto político se la representa.

Recuperando la tradición de los festejos mayas, el Bicentenario de la Revolución de Mayo nos sugiere una visión romántica: épica, colectiva y multitudinaria. La estética romántica implica una praxis excepcional; imagina una democracia $-y$, por lo tanto, una ciudadaníade alta intensidad. La política aparece tangencial a las lógicas de los medios de comunicación. Por su parte los festejos por el Bicentenario de la Independencia, invirtieron esa relación entre política y medios: se privilegió la dinámica televisiva y hasta se tuvieron en cuenta a las redes sociales. La lógica descentralizada ofrece una visión política adaptada a las características del siglo XXI, basada en el respeto de la unión en la diversidad, y en donde lo colectivo se conjuga con la valoración de cada uno en su estricta condición de individuo.

Finalmente, nos queda una reflexión. Sabemos que abordar los discursos en sus múltiples dimensiones -como se ha pretendido aquí- es una tarea compleja, errática y dificultosa, pero creemos que es profundamente necesaria si tenemos la pretensión como investigadores de entender ciertos fenómenos políticos contemporáneos que de ningún modo se ciñen a las palabras de tal candidato o presidente. Contextos políticos cada vez más vertiginosos, en una América Latina convulsionada, en la que izquierdas y derechas se disputan el poder en las urnas, pero también en las calles, en los medios de comunicación tradicionales y en las redes sociales, nos exigen pensar los procesos políticos más allá de las palabras políticos. En eso estamos.

\section{Notas}

1. El concepto que Eric Landowsky ha denominado "régimen de visibilidad" reenvía al problema de la construcción y de la puesta en escena de sujetos individuales y colectivos en función del par conceptual público/privado. Para Landowsky, el pasaje y el cruce de los pares conceptuales (individuo/colectivo, público/privado) obedece a "un principio común, relativo a la admisión o a la exclusión de una instancia testigo ('ellos')". En el nivel 
de la individualidad privada, “yo soy 'yo' [je] en relación a un 'usted' [vous]; pero aquí reunidos, 'nosotros' [nous] nos delimitamos en función de un 'ellos”' (1985: 2). Entendemos que esta noción nos permite abordar el espectáculo político como objeto de estudio, superando un problema recurrente: la exclusión de los "públicos mediáticos".

2. Fuente: https://www.pagina12.com.ar/diario/ultimas/20-146132-2010-05-21.html

3. Grupo teatral dirigido artísticamente por Diqui James, Fabio D'Aquila y Gaby Kerpel cuya estética se vincula, fundamentalmente, a la exploración espacial y a la participación y sorpresa de los espectadores. Anteriormente, los directores habían formado parte de "La Organización Negra" y "De la Guarda".

4. Ver nota en: https://www.ambito.com/paseo-del-bicentenario-federalismo-gastronomia-y-demas-n3624008

5. En un trabajo orientado a estudiar los discursos presidenciales de Cristina Fernández de Kirchner durante el conflicto político entre sectores agropecuarios y el gobierno nacional en Argentina en 2008, Cingolani (2015) identifica tres modalidades de figuración del colectivo oyente, esquematizadas mediante tres tipos de planos visuales de diferentes escalas: el plano individualizante, el plano grupal y el plano generalizante. En primer lugar, el plano individualizante, puede construir entidades a partir de la identificación de alguien específico (“'este es X', donde X conlleva la identificación individual: Juan Gómez, Simón Bolívar, mi abuelo, el cerezo plantado por mis padres, etc."), o de alguien que guarda rasgos estereotípicos y como tal se lo figura como representativo de un colectivo (“'este es un $\mathrm{X}^{\prime}$, donde $\mathrm{X}$ representa una clase: soldado, anciano, hombre de negocios, dama del siglo XIX, árbol, perro, etc.”) (2015: p. 12). En segundo lugar, el plano grupal recorta un grupo donde los que se resaltan son rasgos tipológicos generales, identificatorios de un grupo (no necesariamente extensible a la masa de oyentes): características de género, etarias, étnicas, partidarias, etc., pero también estilísticas, que pueden traducir pertenencia de clase o de sector social. Por último, el plano generalizante construye un conjunto masivo en el sentido de que se trata de un colectivo sólo constituido por su rol de oyente, y es indiferenciado por definición.

6. Según Turner, la communitas, a diferencia de la "comunidad" que se restringe a un "ámbito de vida en común", marca un momento en y fuera del tiempo, dentro y fuera de la estructura social secular (1988: 103). El autor distingue tres arquetipos de communitas: i) la espontánea o existencial, que siempre es una experiencia única, algo que surge de la reciprocidad inmediata, siendo una relación efímera; ii) la normativa, que surge como necesidad de movilizar y organizar los recursos y el imperativo de ejercer un control social entre los miembros del grupo para asegurar la obtención de los fines propuestos al transformarse en un sistema social duradero; iii) la ideológica, expresada en diversos modelos utópicos de sociedad.

7. Según Paveau (2013), la "enunciación patrimonial" es un tipo de filiación discursiva, que consiste en un conjunto de operaciones discursivas que tienen en común el hecho de "constituir herencias colectivas del pasado para un grupo, una cultura, una civilización". La denominación busca designar "las formas por las cuales los locutores evocan explícitamente cuadros anteriores de dimensión patrimonial", colocándose como "herederos de un bien discursivo común" (2013: 175). La mención de un nombre propio es una de esas operaciones. 
8. Las dieciocho escenas representadas fueron: "Los pueblos originarios", "La Argentina", "El éxodo jujeño", "El cruce de los Andes", "El folklore", "La Batalla de Obligado", "La inmigración", "El tango", "Los movimientos políticos sociales", "La industria nacional", "Democracias y Golpes de Estados", "Las Madres de Plaza de Mayo", "Las Malvinas", "El Festejo por el regreso de la Democracia", "Las crisis económicas", "Latinoamérica", "El futuro" y "El rock nacional".

9. En un trabajo posterior, Cingolani (2018) le atribuyó a la modalidad espectáculo la denominación de show, a fin de no generar confusiones, reconociendo que el discurso político siempre fue espectáculo. En este sentido, el semiólogo agrega que el término show no supone una connotación peyorativa, ni se opone a algo que pueda ser considerado más "real" o "espontáneo".

10. Fernández y Cingolani (2010) emplean esta noción, específicamente, para dar cuenta de la estrategia audiovisual de la expresidenta Cristina Fernández de Kirchner. Sin embargo, creemos que es apropiada, también, para abordar las puestas en escena de los dos discursos que ofreció Mauricio Macri con motivo del Bicentenario de la Independencia. En todo caso, restaría precisar las particularidades de uno y otro mandatario respecto de la misma modalidad.

11. El cambio del tamaño de las imágenes del Bicentenario de 2016 respecto a las anteriores se debe a la modificación de proporciones de la transmisión de la TV Pública. Mientras la transmisión de 2010 fue en la relación 4:3, para 2016 el canal estatal ya transmitía en 16:9.

12. Ver al respecto: "Bicentenario: el Gobierno gastó ya \$32,7 millones" (https://www. lanacion.com.ar/politica/bicentenario-el-gobierno-gasto-ya-327-millones-nid1262816); "Los festejos del Bicentenario costarán diez veces menos que los de 2010" (https:// tn.com.ar/politica/los-festejos-del-bicentenario-costaran-diez-veces-menos-que-losde-2010_686347); "Macri prepara un festejo "austero", sin show y deskirchnerizado para el Bicentenario de la Independencia" (https://www.lanacion.com.ar/politica/gobiernofestejos-bicentenario-de-la-independencia-tucuman-macri-nid1902588).

\section{Bibliografía}

Augé, M. (1998). La guerra de los sueños. Barcelona: Gedisa.

Bertoni, L. (1992). Construir la nacionalidad: héroes, estatuas y fiestas patrias 1887-1891. Boletín del Instituto Dr. Emilio Ravignani, 5.

Cingolani, G. (2015). La mediatización, entre los cuerpos ciudadanos y el cuerpo presidencial. En Castro, P. C.: Dicotomía Público / privado, estamos no caminho certo? Maceió: Edufal.

Cingolani, G. y M. Fernández (2019). El cuerpo y el colectivo. Espectáculo y liturgias mediatizadas en los discursos de Cristina Fernández de Kirchner (2008-2015). En Dagatti, M. y Sargentini, V. (comps.): Los pueblos de la democracia. Política y medios en el siglo XXI. Buenos Aires: La Bicicleta Ediciones. 
DaMatta, R. (2002). Carnavales, malandros y héroes. Hacia una sociología del dilema brasileño. México: Fondo de Cultura Económica.

Dayan, D. y E. Katz (1992). Media Events: the live broadcasting of history. Boston: Harvard University Press.

Debray, R. (1995). El Estado seductor. Las revoluciones mediológicas del poder. Buenos Aires: Manantial.

Dubatti, J. (2007). Filosofía del teatro I: convivio, experiencia y subjetividad. Buenos Aires: Atuel.

Gómez, F. (2009). La primera década de Fiestas Mayas (1811-1820). Su aporte para la construcción de legitimidad en el Buenos Aires posrevolucionario. XII Jornadas Interescuelas/Departamentos de Historia. Departamento de Historia, Facultad de Humanidades y Centro Regional Universitario Bariloche. Universidad Nacional del Comahue, San Carlos de Bariloche.

González, M. (2015). Configurar el relato: estética y montaje de imágenes performáticas en los festejos del bicentenario nacional. En Anales del Instituto de Arte Americano e Investigaciones Estéticas. Mario J. Buschiazzo, 45 (2), pp. 119-132.

Halperin Donghi, T. (1997). Revolución y Guerra. Formación de una elite dirigente en la Argentina criolla. Buenos Aires: Siglo veintiuno.

Lipovetsky G. y J. Serroy (2015). La estetización del mundo. Barcelona: Anagrama.

Nun, J. (comp.) (con la colab. de A. Grimson) (2005). Debates de Mayo. Nación, cultura y política. Buenos Aires: Gedisa.

Paveau, M. A. (2013). Os Pré-discursos: sentido, memória, cognição. Campinas: Pontes Editores.

Rosanvallon, P. (2012). La sociedad de los iguales. Buenos Aires: Manantial.

Sigal, S. (2006). La Plaza de Mayo. Una crónica. Buenos Aires: Siglo veintiuno.

Turner, V. (1988). El proceso ritual. Madrid: Taurus.

Verón, E. (1983). Il est là, je le vois, il me parle. En Communications, 38, pp. 98-120.

Verón, E. (1987). La palabra adversativa. Observaciones sobre la enunciación política. En Verón, E. y otros: El discurso político. Lenguajes y acontecimientos. Buenos Aires: Hachette.

\begin{abstract}
The article aims to make a comparative study of the visibility regimes and the ways of representation that are organized around the Argentine national State in the celebrations for the Bicentennials of the May Revolution (May 25, 2010) and Independence (July 9, 2016). On the one hand, seeks to identify the official images, their dominant aesthetics and the ways of organizing their staging and mediatization, in events organized by two administrations with different political sign and with dissimilar ideological orientations, Frente para la Victoria and Cambiemos. On the other hand, it seeks to analyze in each case the meaning production mechanisms and its power in the construction of different groups.
\end{abstract}


Keywords: Image - politics - show - mediation - State - identification groups.

Resumo: $\mathrm{O}$ artigo tem como objetivo fazer um estudo comparativo dos regimes de visibilidade e dos modos de representação organizados em torno do Estado nacional argentino nas comemorações dos Bicentenários da Revolução de Maio (25 de maio de 2010) e Independência ( 9 de julho de 2016). Por um lado, trata-se de identificar as imagens oficiais, sua estética dominante e as formas de organizar sua encenação e midiatização, em eventos organizados por dois governos de signos políticos diferentes e com orientações ideológicas diferentes, a da Frente para a Vitória e Vamos mudar. Por outro lado, trata-se de analisar em cada caso os mecanismos de produção de significado e seu poder na construção de diferentes grupos de identificação.

Palavras-chave: Imagem - política - espetáculo - mediação - Estado - grupos de identificação.

[Las traducciones de los abstracts fueron supervisadas por el autor de cada artículo] 